Published by Munksgaard, Copenhagen, Denunark

No part may be reproduced by any process without written permission from the author(s)

\title{
Studies on Recombination within the Mouse H-2 Complex
}

I.

\section{Three Recombinants Which Position the Ss Locus within the Complex}

\author{
D. C. Shreffler and C. S. David \\ Department of Human Genetics \\ University of Michigan \\ Ann Arbor, Michigan, U.S.A.
}

\begin{abstract}
A series of genetic crosses conducted to map the $S$ s serum variant with respect to the $H-2$ complex is described in detail. Three intra- $H-2$ recombinants were detected. These crossovers, designated $H-2 \mathrm{al}, H-2 \mathrm{ol}$ and $H-2+1$, position the $S s$ gene in the middle of the $H-2$ complex between the regions $H-2 K$ and $H-2 D$. The production of eight new congenic resistant inbred strains is also described.
\end{abstract}

Received for publication 24 January, accepted 14 February 1972

The Ss (serological serum variant) system of the mouse is characterized by large quantitative differences in serum level of a specific protein, detected on immunodiffusion with a rabbit antiserum and under the control of a single gene, $S s$ (Shreffler \& Owen 1963). This gene was shown to be very closely linked to the complex chromosomal region controlling histocompatibility-2 $(H-2)$ antigens; in a series of linkage studies, no recombination between $S s$ and $H-2$ was found (Shreffler 1964). However, one intra- $H-2$ cross-over was detected which upon detailed serological ana- lysis (Shreffler et al. 1966) appeared to position $S$ s either within the complex $H-2$ chromosomal region (hereafter referred to as the $H-2$ complex), or just outside it at the "K-end" as defined by Gorer \& Mikulska (1959).

This paper presents detailed data on a further series of linkage studies, which were designed specifically to detect intra$H-2$ recombination for the purpose of mapping $S s$ with respect to the several separable regions of the $H-2$ complex which control different $H-2$ antigens. The detection of three new cross-overs which position Ss 
RECOMBINATION WITHIN It- 2 COMPLEX

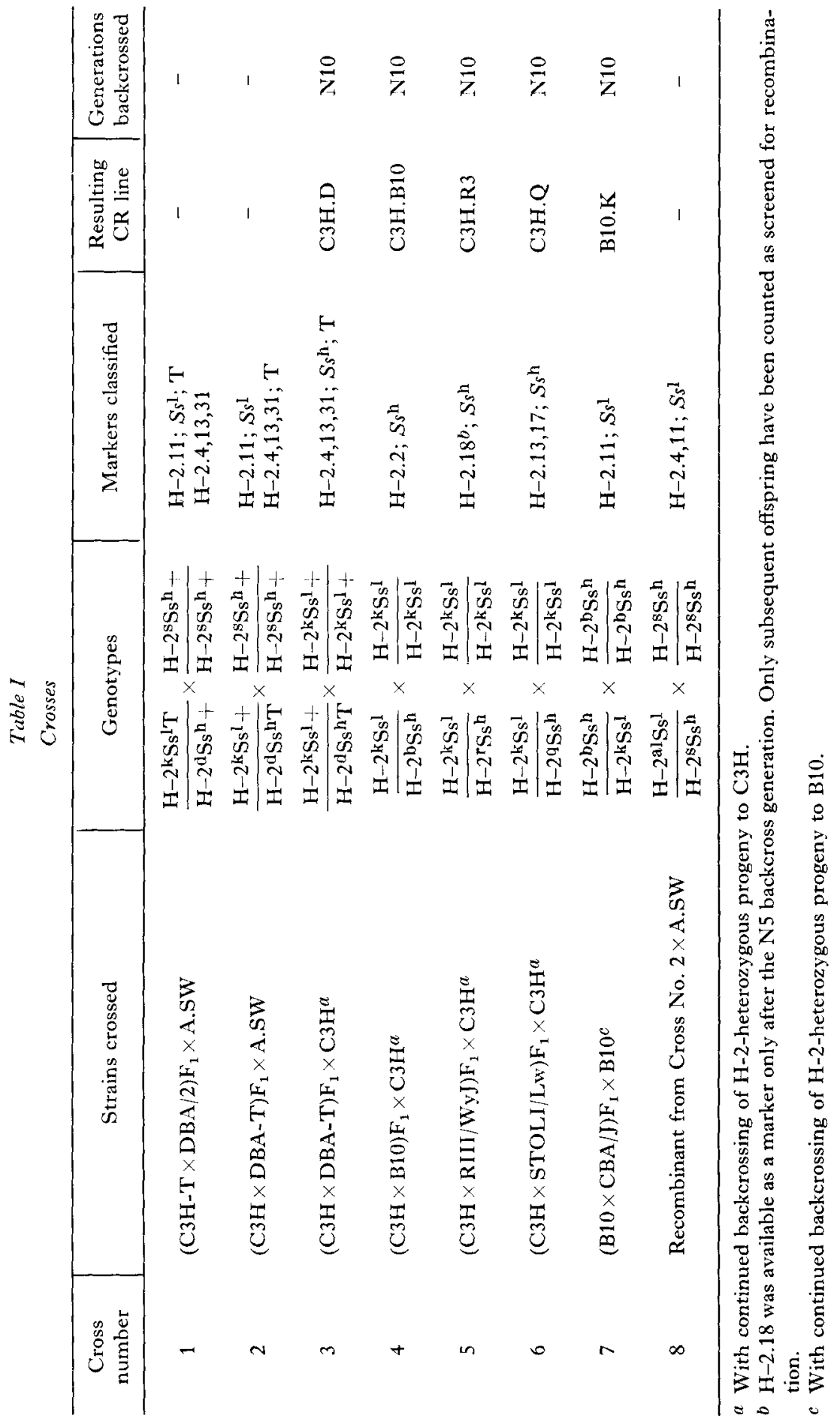


within the $H-2$ complex is described. In a subsequent paper (David \& Shreffler 1972) we will present detailed serological analyses of these three recombinants and of a fourth, detected by Stimpfling (1965), which is very similar to one of ours. Preliminary data and interpretations regarding these cross-overs have already been presented (Shreffler 1963, Shreffler 1967, David et al. 1969).

\section{Materials and Methods}

Typ Strains - The inbred lines used as type strains for the various $H-2$ chromosomes are listed in the second paper of this series (I)avid \& Shreffler 1972).

Crosses - A number of crosses involving both $S_{s}$ and $H-2$ differences were made to screen for recombination within the $H-2$ complex. All crosses involved the $H-2 k S s^{l}$ chromosome in various heterozygous combinations. Most of the crosses followed the continuous backcrossing pattern used in similar studies by Stimpfling \& Richardson (1965), such that five of the eight crosses resulted in new congenic resistant inbred strains. These crosses are summarized in 'Table I. All crosses were made in reciprocal sex combinations, i.e. both male and female heterozygous parents were used in about equal numbers for every cross. The C3H-T and DBA-T stocks in crosses 1-3 were not inbred. They were produced by outcrossing to tailless stocks to introduce the Brachyury $(T)$ marker, as previously described (Shreffler 1964). Crosses 3 and 4 are continuations of crosses previously described (Shreffler 1964, Crosses 5 and 1); complete data for the entire series are published here. The $H-2, S s$ and $T$ markers which were classified in each cross are listed in column 4. From crosses 3 through 7 , new congenic strains were established as indicated in columns 5 and 6 . Some studies on the C3H.Q strain have been de- scribed previously (Shreffler \& Snell 1969). Cross 8 was initially set up as a progeny test of one of two intra- $H-2$ recombinants found in Cross 2. It is included here because it subsequently produced another one of the recombinants described in this paper.

It was planned in advance that for Crosses 4 through 7 the total number of progeny produced in each cross would be determined by the number required to produce the various congenic lines, thus providing an unbiased estimate of recombination frequency. For Crosses $1-3$, all $H-2 \mathrm{k}$ /

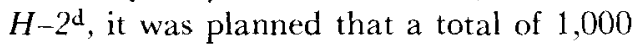
progeny would be produced. In fact, only 908 were actually screened. For Cross 8, the number was not predetermined, so any recombination frequency for this cross cannot be regarded as entirely unbiased.

H-2 Typing - All classifications of $\mathrm{H}-2$ markers in these studies were done by the PVP hemagglutination method previously described (Shreffler et al. 1966). The antisera employed are listed in Table II. The specificity of each antiserum is noted. Although none was made in a congenic strain combination, all were analyzed as previously described (Shreffler et al. 1966) to establish that, for the conditions under which they were employed, no non- $H-2$ antibodies interfered, except as noted for $\mathrm{H}-2.2$.

Ss Typing - Quantitative variation in the $\mathrm{Ss}$ protein was assayed by immunodiffusion with a rabbit anti-Ss antiserum, made specific by absorption. The antiserum was prepared against the fraction of C57BL/10J $\left(\mathrm{Ss}_{\mathrm{s}-\mathrm{H}}\right)$ serum which was excluded from Sephadex G-200 gel filtration medium and equilibrated with phosphate buffered saline. Two injections of an amount of this fraction equivalent to $1 \mathrm{ml}$ of original serum were given intraperitoneally with Freund's complete adjuvant, with an interval of two weeks. Two weeks after the second injection, the same amount was 
Table II

H-2 Antisera used to detect markers

\begin{tabular}{|c|c|c|}
\hline Marker & Strain combination & Comments \\
\hline $\mathrm{H}-2.2$ & $\begin{array}{l}(\mathrm{C} 3 \mathrm{H} \times \mathrm{DBA} / 2) \mathrm{F}_{1} \text { anti-B10 } \\
{[\mathrm{k} \times \mathrm{d} \text { anti-b }]}\end{array}$ & $\begin{array}{l}\text { Could contain anti- } 22 \text { and anti-33, but very } \\
\text { weak by hemagglutination test. Alsocontained } \\
\text { antibody to non- } \mathrm{H}-2 \text { antigen, but antigen } \\
\text { eliminated in second generation of Cross } 4 \text {. }\end{array}$ \\
\hline $\mathrm{H}-2.4$ & $\begin{array}{l}(\mathrm{C} 3 \mathrm{H} \times \mathrm{STOLI} / \mathrm{Lw}) \mathrm{F}_{1} \text { anti-DBA } / 2 \\
{[\mathrm{k} \times \mathrm{q} \text { anti-d }]}\end{array}$ & Could contain anti-31, but not present. \\
\hline $\mathrm{H}-2.11$ & $\begin{array}{l}(\mathrm{DBA} / 2 \times \mathrm{B} 10) \mathrm{F}_{1} \text { anti-C } 3 \mathrm{H} \\
{[\mathrm{d} \times \mathrm{b} \text { anti-k }]}\end{array}$ & $\begin{array}{l}\text { In fact, anti } 11,23 \text {. Could also contain anti- } 1 \\
\text { and anti-32, but very weak. }\end{array}$ \\
\hline $\mathrm{H}-2.13$ & $\begin{array}{l}(\mathrm{C} 3 \mathrm{H} \times \mathrm{B} 10) \mathrm{F}_{1} \text { anti-DIBA } / 1 \\
{[\mathrm{k} \times \mathrm{b} \text { anti-q] }} \\
(\mathrm{C} 3 \mathrm{H} \times \mathrm{B10}) \mathrm{F}_{1} \text { anti-A } \\
{[\mathrm{k} \times \mathrm{b} \text { anti-a }]}\end{array}$ & $\begin{array}{l}\text { Also contained anti-17,30, but used only for } \\
\text { Crosses } 1,2,3,4,5,7 \text {, where } 17 \text { and } 30 \text { not } \\
\text { involved. } \\
\text { Also contained anti-4, but used only for } \\
\text { Cross } 6 \text {, where } 4 \text { not involved. }\end{array}$ \\
\hline $\mathrm{H}-2.17$ & $\begin{array}{l}A \text { anti-DBA } / 1 \\
\text { [a anti-q] }\end{array}$ & Also contained anti-30, but much weaker. \\
\hline $\mathrm{H}-2.18$ & $\begin{array}{l}\mathrm{C} 3 \mathrm{H} \text { anti-RIII/ } \mathrm{W}_{\mathrm{y} J} \\
{[\mathrm{k} \text { anti-r }]}\end{array}$ & Could contain anti-R(rho), but not present. \\
\hline $\mathrm{H}-2.19$ & $\begin{array}{l}\text { A anti-A.SW } \\
\text { [a anti-s] }\end{array}$ & $\begin{array}{l}\text { Could contain anti- } 7 \text {, but used only early } \\
\text { bleedings, which did not. }\end{array}$ \\
\hline $\mathrm{H}-2.31$ & $\begin{array}{l}\text { A anti-DBA } / 2 \\
{[\text { a anti-d] }}\end{array}$ & Specific, though weak and variable. \\
\hline
\end{tabular}

given intraperitoneally without Freund's adjuvant, and on the succeeding day the same amount without Freund's adjuvant was given intravenously. The rabbit was bled several times from 6 to 14 days after the last injection. Booster immunizations consisted of the last two injections of the above schedule. Antibodies to non-Ss proteins were removed by absorption with whole $\mathrm{C} 3 \mathrm{H}\left(\mathrm{Ss}_{\mathrm{s}}-\mathrm{L}\right)$ serum, as previously described (Shreffler \& Owen 1963), usually at a ratio of about 1 volume absorbing serum to 5 volumes antiserum.

Two immunodiffusion methods were employed, depending upon the cross to be screened. For crosses 3, 4, 5 and 6, where the $\mathrm{S}_{\mathrm{s}}-\mathrm{L}$ and $\mathrm{Ss}-\mathrm{HL}$ phenotypes segregated, a simple Ouchterlony micro-slide method was employed. $2.5 \times 7.5 \mathrm{~cm}$ glass slides were layered with $2.5 \mathrm{ml}$ agar me- dium (1.5\% Bactoagar, $0.72 \% \mathrm{NaCl}$, $0.60 \% \mathrm{Na}$ citrate, $.001 \% \mathrm{Na}$ azide, $\mathrm{pH}$ adjusted with $\mathrm{HCl}^{\mathrm{l}}$ to 6.7 ). Hexagonal patterns with wells $2.5 \mathrm{~mm}$ in diameter and $9 \mathrm{~mm}$ apart were employed, with anti-Ss in the center well and test sera in the outer wells. Slides were incubated overnight at $37^{\circ}$. Under these conditions, Ss-L and Ss-HL types are readily distinguished, as previously described (Shreffler \& Owen 1963).

For crosses 1, 2, 7 and 8, in which the $\mathrm{Ss}-\mathrm{H}$ and $\mathrm{Ss}-\mathrm{HL}$ phenotypes segregated, a more sensitive method was required. Double diffusion in tubes was employed, modified from Preer (1956). A mixture of equal volumes of anti-Ss serum and $1 \%$ Ionagar No. 2 (Consolidated Labs, Chicago Heights, Ill.) in $0.85 \mathrm{NaCl}$ solution was prepared (both components of the mixture were first 
brought to $\left.50^{\circ}\right)$. A layer of $0.04 \mathrm{ml}$ of this mixture was pipetted into the bottom of a $6 \times 50 \mathrm{~mm}$ culture tube and allowed to gel. On top of this layer, $0.3 \mathrm{ml}$ of $0.5 \%$ Ionagar in $0.85 \% \mathrm{NaCl}$ solution was layered and allowed to gel. Finally, $0.01 \mathrm{ml}$ mouse serum for testing was layered on top and the tube was sealed with paraffin. Tubes were incubated vertically for 72 hours at $37^{\circ}$. Levels of $S$ s protein in the test sera were quantitated by comparing an $\mathrm{R}_{\mathrm{f}}$ value (the distance from the top of the $0.3 \mathrm{ml}$ agar layer to the leading edge of the precipitin band divided by the total length of the 0.3 $\mathrm{ml}$ agar layer) for each serum, with a calibration curve constructed from the $R_{\mathrm{f}}$ values for serial dilutions of a standard, reference ( $\mathrm{Ss}-\mathrm{H}$ ) serum. The $\mathrm{R}_{\mathrm{f}}$ values ( $\mathrm{Ss} \mathrm{lev-}$ els) for $\mathrm{S}_{\mathbf{s}}-\mathrm{H}$ and $\mathrm{Ss}_{\mathbf{s}}-\mathrm{HL}$ sera fell into two discrete populations, differing by about two-fold, with only infrequent overlaps. In any case of questionable Ss type, the animal was retested. If this failed to clearly resolve the question, the animal was progeny-tested.

\section{Results}

The results of the eight crosses are summarized in Table III. Three recombinants were detected among the 2,212 progeny screened. Two were found in the same litter from Cross 2 (one male, one female), one more was found among the progeny of the male recombinant from Cross 2. Three aspects of the segregation data in Table III are noteworthy. The recombination frequencies for $\mathrm{T}-\mathrm{H}-2$ in Crosses 1-3 are consistent with previously reported values ( $14.8 \%$ for Cross 1, $15.1 \%$ for Cross 2 plus Cross 3 ). In Crosses 1-3, all involving $H-2^{\mathrm{k}} / H-2^{\mathrm{d}}$ heterozygotes, there is a distortion of segregation in favor of the $H-2^{\mathrm{k}}$ allele, significant at the 0.05 level $\left(\chi^{2}=\right.$ 4.8). Approximately the same deviation is found in all three crosses, so this does not relate to phase of linkage with $T$. This may reflect some selective advantage for $H-2^{\mathrm{k}}$ over $H-2^{\mathrm{d}}$, but there is no indication of any advantage for $H-2^{\mathrm{k}}$ in the other crosses involving $H-2^{\mathrm{k}}$ (Crosses 4-7). The most important aspect of the data in Table III is that no simple recombination between $S s$ and $H-2$ has been found among the 2,212 progeny, thus supporting previous findings (Shreffler 1964).

From Crosses 3-7, five new congenic resistant strains have been established as indicated in Table I. Following ten generations of backcrosses, each strain has thus far undergone at least seven additional generations of sib-mating. All are homozygous for the transferred allele. Skin graft tests for congenicity of each strain with the background strain are in progress and will be reported at a later time.

The $H-2, S$ s and $T$ markers of the three recombinants and the parental animals are summarized in Table IV. Note in particular the summary of markers present and absent. In each case, the original recombinant animal was detected either by a new combination of markers (for 750 and Q59), or by loss of a marker (for $0^{722}$ ), as listed in column 4. The altered combinations were verified by retyping, then by progeny test. O'50 was progeny-tested by crosses to A.SW and C3H females. (As indicated above, $\mathrm{O}^{7} 22$ was detected among the offspring of the progeny test of $0^{7} 50$ by an A.SW female). 59 was crossed to both $\mathrm{C} 3 \mathrm{H}$ and $\mathrm{B} 10$ males, at different times. O'22 was crossed to A.SW and C.3H females. The cross to $\mathrm{C} 3 \mathrm{H}$ provided additional confirmation of the $0^{7} 22$ crossover, in that the progeny which were $\mathrm{H}-2.4,-13,-11$ were found also to be positive for $\mathrm{H}-2.19$, indicating that, concomitant with the loss of $\mathrm{H}-2.11$, there was a gain of $\mathrm{H}-2.19$. The presence or absence of the $\mathrm{H}-2$ markers indicated in Table II was also confirmed by in vivo absorptions for each marker. Details of 
Table III

Summary of $\mathrm{H}-2-\mathrm{Ss}$ and $\mathrm{T}$ segregation data from crosses

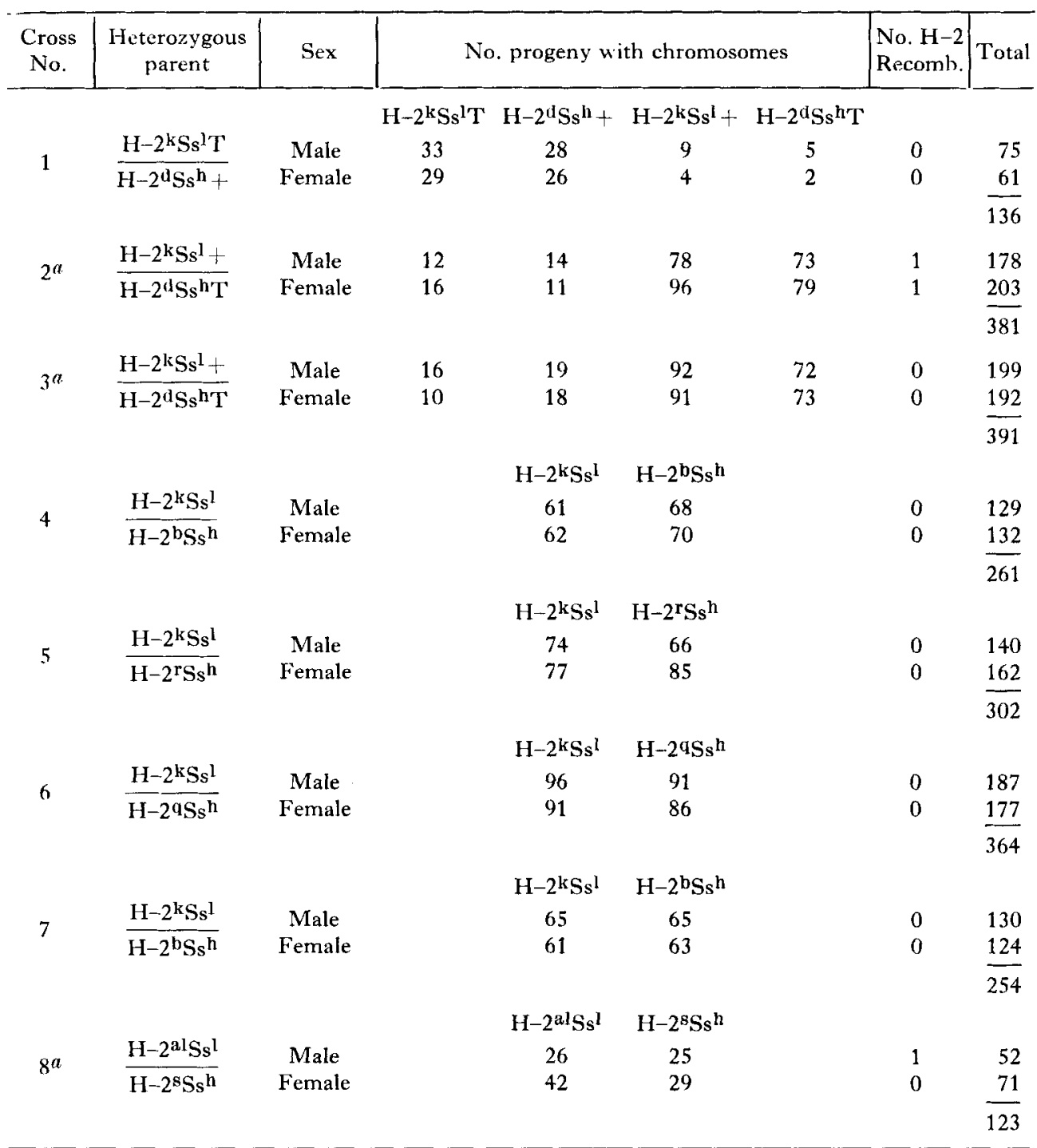

a. Partial data from these crosses were reported previously (Shreffler 1965). The data presented here are the full and final results for these crosses, including those reported previously.

these and further analyses are included in the second paper of this series (David \& Shreffler 1972).

The allele symbols assigned to the three recombinants are listed in the sixth column of Table IV. In a previous publication
(Shreffler 1967), these were designated $H-2^{\mathrm{a}-\mathrm{Sf}} S s^{1}, H-2^{\mathrm{o}-2 S f} S s^{\mathrm{l}}$ and $H-2^{\mathrm{t}} S s^{\mathrm{l}}$. Consistent with the suggestions of Snell et al. (1964) relating to use of double-letter symbols for new $\mathrm{H}-2$ alleles which are minor variants of previously defined alleles, we 
Table IV

Recombination of markers in three intra- $\mathrm{H}-2$ crossovers

\begin{tabular}{|c|c|c|c|c|c|c|}
\hline \multirow{2}{*}{$\begin{array}{c}\text { Animal } \\
\text { No. }\end{array}$} & \multirow{2}{*}{$\begin{array}{l}\text { Parental } \\
\text { genotype }\end{array}$} & \multirow{2}{*}{$\begin{array}{l}\text { Parental } \\
\text { markers }\end{array}$} & \multicolumn{2}{|c|}{ Recombinant } & \multirow{2}{*}{$\begin{array}{c}\text { Allele } \\
\text { designa- } \\
\text { tion }\end{array}$} & \multirow{2}{*}{$\begin{array}{l}\text { CR lines } \\
\text { produced }\end{array}$} \\
\hline & & & $\begin{array}{l}\text { Markers } \\
\text { present }\end{array}$ & $\begin{array}{l}\text { Markers } \\
\text { absent }\end{array}$ & & \\
\hline \multirow{2}{*}{$\checkmark 50$} & $\mathrm{H}-2^{\mathrm{k}} \mathrm{Ss}^{\mathbf{1}+}$ & $\mathrm{H}-2.11: \mathrm{Ss}^{\mathrm{l}}$ & $\mathrm{H}-2.11 ; \mathrm{Ss}^{\mathrm{l}}$ & - & \multirow{2}{*}{$\mathrm{H}-2^{\mathrm{al}}$} & \multirow{2}{*}{ A.AI } \\
\hline & $\mathrm{H}-2^{\mathrm{d}} \mathrm{Ss}^{\mathrm{h}} \mathrm{T}$ & $\mathrm{H}-2.4,13,31 ; \mathrm{T}$ & $\mathrm{H}-2.4,13$ & $\mathrm{H}-2.31 ; \overline{\mathrm{T}}$ & & \\
\hline \multirow{2}{*}{ 누 59} & $\mathrm{H}-2^{\mathrm{k}} \mathrm{Ss}^{1}+$ & $\mathrm{H}-2.11 ; \mathrm{Ss}^{\mathrm{I}}$ & $\mathrm{Ss}^{1}$ & $\mathrm{H}-2.11$ & \multirow{2}{*}{$\mathrm{H}-2^{\mathrm{ol}}$} & \multirow{2}{*}{$\mathrm{C} 3 \mathrm{H} . \mathrm{OL}$} \\
\hline & $\mathrm{H}-2^{\mathrm{d}} \mathrm{Ss}^{\mathrm{h}^{\mathrm{n}} \mathrm{T}}$ & $\mathrm{H}-2.4,13,31 ; \mathrm{T}$ & $\bar{H}-2.31 ; \bar{T}$ & $\overline{\mathrm{H}}-2.4,13$ & & \\
\hline \multirow{2}{*}{$\sigma 22$} & $\mathrm{H}-2^{\mathrm{al}} \mathrm{Ss}^{\mathrm{l}}$ & $\mathrm{H}-2.4,11,13 ; \mathrm{Ss}^{1}$ & $\mathrm{H}-2.4,13 ; \mathrm{Ss}^{1}$ & $\mathrm{H}-2.11$ & \multirow{2}{*}{$\mathrm{H}-2^{\mathrm{tl}}$} & \multirow{2}{*}{ A.TI } \\
\hline & $\mathrm{H}-2^{\mathrm{sSs}} \mathrm{s}^{\mathrm{h}}$ & - & - & - & & \\
\hline
\end{tabular}

have adopted the less cumbersome notations shown in Table IV. The O'50 recombinant is thus designated $H-2^{\text {al }}$, because it is indistinguishable from $H-2^{\text {a }}$ for the H-2 specificities (David \& Shreffler 1972), but is $S s^{\downarrow}$ instead of $S s^{h}$. Likewise, $H-2^{\text {ol }}$ is assigned to the 959 recombinant type which is identical to $H-2^{\text {oh }}$ for $\mathrm{H}-2$ antigens (previously designated $H-2 \circ S_{s}$ (Shreffler et al. 1966) (David \& Shreffler 1972), but is $S_{s}$ instead of $S_{s^{\mathrm{h}}}$ ). The recombinant allele of $\sigma^{\prime \prime 2} 2$ is designated $H-2^{\text {tl }}$ to distinguish it from the very similar $H-2^{\text {th }}$ of Stimpfling (1965) (cf. David \& Shreffler 1972).

The new alleles have been preserved on inbred backgrounds by production of congenic resistant strains, as indicated in the last column of Table IV. The A.AL and A.TL strains were produced by five generations of backcrossing to the A.SW (old) strain (which was not entirely congenic with $\mathrm{A} / \mathrm{W}_{\mathrm{ySn}}$ ), followed by six generations of backcrossing to A.CA. Each strain has since undergone at least five additional generations of sib mating to produce a homozygous line. The $H-2^{\text {oh }}$ allele previously described (Shreffler et al. 1966) and the $H-2^{\text {ol }}$ allele have both been transferred to $\mathrm{C} 3 \mathrm{H} / \mathrm{JSf}$ background by 11 and 10 generations of backcrossing respectively.
Both lines have since undergone five or more generations of sib-mating and are homozygous for the recombinant alleles. Skin graft tests for congenicity of these lines with the background strain are in progress and will be reported at a later time. Preliminary data indicate that all of these strains are probably congenic with the background strain.

\section{Discussion}

These three recombinants, taken together with the $H-2^{\text {oh }}$ recombinant previously described (Shreffler et al. 1966), strongly indicate that the $S_{s}$ locus maps inside the $H-2$ complex, between the genetic determinants for specificities $\mathrm{H}-2.4$ and $\mathrm{H}-2.13$ ( $H-2 D$ region) on one side and for $\mathrm{H}-2.11$ and $\mathrm{H}-2.31$ ( $H-2 \mathrm{~K}$ region) on the other (cf. Shreffler 1965). This position within the $H-2$ complex is further supported by the data of Passmore \& Shreffler (1970), which establish a similar position for the Slp allotypic variant of the Ss protein. The relevance of the three recombinants reported here to the $H-2$ "fine structure" map is discussed in further detail in the next paper of this series (David \& Shreffler 1972). The recombinants in Cross No. 2 also provide further evidence that the 
Brachy $(T)$ marker is located at the $H-2 K$ end of the $H-2$ complex (cf. Stimpfling \& Richardson 1965).

The recombination frequencies for the crosses studied here are somewhat lower than the $0.36 \%$ previously reported by Stimpfling \& Richardson (1965). For all crosses reported in this study, the frequency is $3 / 2212=0.13 \%$, including Cross No. 8 , which was not an entirely random sample. For the $H-2^{\mathrm{d}} / H-2^{\mathrm{k}}$ heterozygous combination only, the recombination frequency was $2 / 908=0.22 \%$, still lower than the frequency for the $H-2^{\mathrm{a}} / H-2^{\mathrm{b}}$ combination studied by Stimpfling. It may be of some significance that no recombination was found in the $H-2^{\mathrm{b}} / H-2^{\mathrm{k}}, H-2^{\mathrm{q}} / H-2^{\mathrm{k}}$ and $H-2^{\mathrm{r}} / H-2^{\mathrm{k}}$ combinations. Stimpfling \& Richardson (1965) screened 839 progeny from $H-2^{\mathrm{b}} / H-2^{\mathrm{k}}$ parents and found no recombinants. When this is combined with the 515 progeny screened from the same combination in the present study, it indicates that the frequency for this combination must be very low indeed. Crossing-over apparently does occur in this combination, however, since Amos (personal communication) has recently found a $H-2^{\mathrm{b}}$ $/ H-2^{\mathrm{k}}$ cross-over. In any event, the generally low recombination frequency associated with the $H-2 \mathrm{k}$ allele raises the question whether this chromosome may have unusual properties which depress crossingover.

The apparent "clustering" of recombinants in the present study deserves comment, although no explanation can be offered. It would seem to be more than mere coincidence that $\sigma^{\top} 50$ and 759 occurred in the same litter and that $O^{\prime 2} 22$ was subsequently detected among the progeny of $0^{7} 50$. Whether this reflects environmental effects, chromosomal instability, or other factors, can only be speculated upon. We have, however, observed other instances in which multiple recombinants have ap- peared very close together in time (unpublished observations).

The congenic resistant recombinant strains which have been produced should be of particular value in further investigations of the Ss trait. Each strain forms a pair with another existing congenic strain in which both members are apparently identical with respect to $\mathrm{H}-2$ alloantigenic specificities, but differ in Ss type, viz. C3H.OL $\left(H-2^{\text {ol }}\right)$ with C3H.OH $\left(H-2^{\text {oh }}\right)$, A.AL $\left(H-2^{\mathrm{a} l}\right)$ with A $\left(H-2^{\mathrm{a}}\right)$ and A.TL $\left(H-2^{\text {tl }}\right)$ with A.TH $\left(H-2^{\text {th }}\right)$. (See David \& Shreffler 1972 for serological details.) For example, skin grafts exchanged between $\mathrm{C} 3 \mathrm{H} . \mathrm{OL}$ and $\mathrm{C} 3 \mathrm{H} . \mathrm{OH}$ survive indefinitely, indicating that no $\mathrm{H}-2$ antigenic difference is associated with the Ss serum protein difference (Shreffler, unpublished data). Further studies of this type will perhaps be useful in elucidating the nature of the Ss difference.

\section{Acknowledgements}

The excellent technical assistance of $\mathrm{Mr}$. Dale Wartluff and Miss Patricia Zygowicz during these studies is gratefully acknowledged. We are also most grateful to Dr. Morris Foster for providing animal space in the Mammalian Genetics Center during the period of these investigations.

\section{References}

David, C. S. \& Shreffler, D. C. (1972) Studies on recombination within the mouse $\mathrm{H}-2$ complex. II. Serological analyses of four recombinants, $H-2$ al,$H-2$ ol,$H-2^{\text {tl }}$ and $H-2^{\text {th }}$. Tissue Antigens, 241-249.

David, C. S., Shreffler, D. G. \& Stimpfling, J. H. (1969) Analyses of four crossovers within the complex $H-2$ region of the house mouse. Genetics 61, s12-s13. (Abstract).

Gorer, P. A. \& Mikulska, Z. B. (1959) Some further data on the $\mathrm{H}-2$ system of antigens. Proc. roy. Soc. B 151, 57-69.

Passmore, H. C. \& Shreffler, D. C. (1970) A 
sex-limited serum protein variant in the mouse: Inheritance and association with the $H-2$ region. Biochem. Genet. 4, 351-365.

Preer, J. R. (1956) A quantitative study of a technique of double diffusion in agar. J. Im munol. 77, 52-60.

Shreffler, D. C. (1964) A serologically detected variant in mouse serum: Further evidence for genetic control by the histocompatibility-2 locus. Genetics 49, 629-634.

Shreffler, D. C. (1965) The Ss system of the mouse - a quantitative serum protein difference genetically controlled by the $\mathrm{H}-2$ region. Isoantigens and Cell Interactions, ed. Palm, J. p. 11-19. Wistar Inst. Press, Phila.

Shreffler, D. C. (1967) Genetic control of cellular antigens. Proc. 3rd Int. Congr. Human Genet., ed. Crow, J. \& Neel, J. p. 217-231. Johns Hopkins Press, Baltimore.

Shreffler, D. C., Amos, D. B. \& Mark, R. (1966) Serological analysis of a recombination in the $\mathrm{H}_{-2}-2$ region of the mouse. Transplantation 4, 300-322.
Shreffler, D. C. \& Owcn, R. D. (1963) A serologically detected variant in mouse serum: Inheritance and association with the histocompatibility-2 locus. Genetics 48, 9-25.

Shreffler, D. C. \& Snell, G. D. (1969) The distribution of thirteen $H-2$ alloantigenic specificities among the products of eighteen $\mathrm{H}_{-2}$ alleles. Transplantation 8, 435-450.

Stimpfling, J. H. (1965) Immunogenetics of mouse cellular isoantigens. Isoantigens and Cell Interaction, ed. Palm, J., p. 5-10. Wistar Inst. Press, Phila.

Stimpfling, J. H. \& Richardson, A. (1965) Recombination within the histocompatibility-2 locus of the mouse. Genetics 51, 831-846.

\section{Address:}

D. C. Shreffler

Department of Human Genetics

University of Michigan

Ann Arbor, Michigan

U.S.A. 